\title{
CRIME AND MENTAL DISORDER: \\ A LITERATURE REVIEW
}

\author{
Hulathduwa S.R.
}

Senior Lecturer, Dept. of Forensic Medicine, Faculty of Medical Sciences, University of Sri Jayawardenepure, Sri Lanka

\begin{abstract}
Conceptual uncertainty exists surrounding the term "mental disorder". It is generally possible to locate a physical cause for physiological diseases making the diagnosis more precise and accurate. In contrary to this, the attribution of "mental disorder" is a subjective assessment usually formed within a given medical and legal framework of the country, mostly influenced by the culture, religion and other sociological factors too. The word "disorder" is the preferred generic term in psychiatry today as classification and labeling of certain mental conditions/states as "illnesses" is a focus of debate. Since the beginning of the human history, the society has associated mental disorders with crime; particularly the more violent forms of crime. Public opinion surveys show that people across the globe think that mental disorder and crime go hand in hand- a misconception revived and propagated mostly by the media. For example, a national survey conducted in 2006 found that $60 \%$ of Americans thought that people with schizophrenia were likely to act violently toward others. This article attempts to review the current literature so as to better visualize the yet unsettled proposition of crime and mental disorder.
\end{abstract}

Key words: violence, mental disorder, crime, schizophrenia, sociopathic disorder

Corresponding author:

sanjayah@hahoo.co.uk

\section{INTRODUCTION}

The phrase "crime and mental disorder" could be looked at in several angles. Is there any association between the mental disorders and crimes/violent behavior? If so, what are the specific types of mental disorders that could be linked with crime? What are the common types of crimes committed by the mentally disorderly? Are individuals with mental disorders more prone to be victims of crimes? If so, what types of crimes are more likely to be committed on such individuals? People with mental illnesses/disorders may be at a greater risk of arrest. ${ }^{1}$ In a study conducted by Teplin in 1984-85 in the USA, out of 506 persons suspected of committing a crime, 30 were suffering from a mental disorder. This study showed that a significantly high proportion $(47 \%$ against $28 \%$ ) of those with mental disorders was arrested compared to those who were mentally healthy. However, there was no significant difference between the types of crimes suspected to have been committed by the two groups. This study could not establish that the mentally disorderly are more prone to criminal behaviour. After extensively reviewing the recent literature, Bonta and others established that the mentally disordered offenders did not show a greater tendency to commit crimes than the mentally healthy. ${ }^{2}$ When trying to establish or refute the association between crime and mental disorders, it could be investigated in two angles: the prevalence of mental disorder in a population of known criminals and the prevalence of criminal behavior among known psychiatric patients. 


\section{DISCUSSION}

\section{Mental disorders among criminals}

In the developed world, there is a tendency that many mentally disordered offenders would be filtered out of the criminal justice system at an early stage. Therefore most of the studies are based on prison populations. Very few researches had been conducted on court samples. Coid describes two such studies, one as early as in 1940s. ${ }^{3}$ Both indicated relatively low rates of mental disorders among criminals. More recent studies suggest that psychological problems are common among prison populations. Gunn et al. in 1991 have conducted an extensive survey among $5 \%$ of the male prisoners in England serving a sentence of six months or more and found that $37 \%$ of them were suffering from some kind of psychological disorder. ${ }^{4}$ In a similar survey conducted by the same authors in 1978, (13 years prior to the one mentioned above as reference 4) it was revealed that $31 \%$ of convicted prisoners were suffering from some sort of psychological disorder. ${ }^{5}$ In both occasions the prevalence of major psychotic disorders among the prisoners was $2 \%$. In another study conducted by Taylor on both male and female life-sentence inmates in London prisons, it was revealed that the prevalence of major psychotic disorders among them was as high as $10 \%$, schizophrenia being the commonest. ${ }^{6}$ Teplin claimed that presence of severe mental illness among prison populations varied between 4\%-12\%. ${ }^{7}$ Birmingham and others on their study on remand prisoners in Durham, found that $26 \%$ of them had suffered from one or multiple mental disorders excluding substance abuse. $4 \%$ of them were diagnosed as suffering from major psychiatric illness. ${ }^{8}$ Brooke and others in their study on remand prisoners in thirteen adult prisons and three juvenile institutions in England found that 5\% of them were suffering from major psychotic illness which they estimated as between 4 and 5 times the level found in the general population. ${ }^{9}$ Singleton and others in an extensive research on inmates from entire prison population in
England found that $63 \%$ of male remand prisoners had an anti-social personality disorder while $14 \%$ of female prisoners were psychotic. ${ }^{10}$ Similar findings were revealed by Fazel and Danesh where $3.7 \%$ of male prisoners were suffering from major psychotic illness, $10 \%$ from major depression and $65 \%$ from any form of personality disorder. ${ }^{11}$ Gosden and others found that almost $70 \%$ of male adolescent remand prisoners suffered from any form of mental disorder during the previous twelve months. ${ }^{12} \quad$ Birmingham and others discovered that routine health screening upon reception into prison often failed to identify and detect mental disorder both in the convicted prisoners as well as in remand prisoners. $^{13}$

Though extensive research is available as mentioned above, such findings do not necessarily provide conclusive evidence towards the link between mental disorder and crime. This is due to alternative explanations. For example mentally disordered offenders may be more vulnerable to be "caught' by the public or the law enforcement authorities due to their inept behavior. Furthermore, the police may have a low threshold in charging such individuals. Also, the police and the courts may consider that conviction is the best method to keep them away from the society and provide them with compulsory treatment. Naturally, guilty pleas will be commoner among those with mental disorders. Mental disorder could have been developed subsequent to offending and sometimes as a result of incarceration in undesirable prison conditions itself. ${ }^{14,15}$

\section{Criminal behavior among the individuals with mental disorders}

This is the second approach to investigate a link between crime and mental disorder. Here, the researchers look at the crime rate among psychiatric patients (and compare it with that of the general population). Brennan and others found that those suffering from major psychiatric illness showed a greater risk of arrest for violence. ${ }^{16}$ Steadman and 
others concluded that offending by psychiatric patients was more related to the factors which serve as general predictors of violence (such as age, gender, ethnicity, social class and etc.) than to their mental disorder. ${ }^{17}$ Toch and Adams studied the previous offences of a population of mentally disordered prisoners and found that all of them were going through considerable psychological disturbances by the time they have committed their previous crimes. ${ }^{18}$ Most of the research focuses on the mental illness and violent forms of crimes such as rape and murder. Relatively little research has been conducted on petty crimes such as shop-lifting. Gibbens ${ }^{19}$ and Taylor and Gunn $^{20}$ both suggest that there is an over representation of mental disorder among those convicted for arson or criminal damage. The relationship between mental disorder and risk of violence ("dangerousness") was promoted by the psychiatrists of by-gone era when they could not find a plausible alternative explanation to account for serious crimes. ${ }^{21}$ Though the modern-day psychiatry does not fully support this idea, there is still a common belief that the mentally disorderly are particularly prone to violent behaviour. It is prudent to find out how evidence-based this proposition is. Taylor and Gunn in their research based on remand prisoners either charged with or convicted of a homicide offence; found that $9.3 \%$ showed symptoms of schizophrenia, $1.9 \%$ affective psychosis and 26\% 'mixed disorders'. ${ }^{22}$ Hafner and Boker in their German research concluded that schizophrenia is the type of mental disorder most clearly connected with serious and violent crimes though the percentages are quite low (about 0.05 percent of all schizophrenics). ${ }^{23}$ There is also evidence that people suffering from psychopathic disorder are prone to violent crimes. Black and Spinks found out that psychopaths are more likely to indulge in violent crimes than those suffering from other forms of mental disorders. ${ }^{24}$ Hare and others established a higher recidivism rate for most crimes among the psychopaths than those suffered from other types of mental disorders. ${ }^{25}$ Jameison and Taylor focusing on discharged patients from three English high-security hospitals concluded that two thirds of those classified under the legal category of "psychopathic disorder" have resorted to violent crimes within the next two years of discharge. ${ }^{26}$ There is also evidence that post-traumatic stress disorder (PTSD) could be associated with crime and violence. Solursh studying a sample of 100 American Vietnam-War veterans suffering from PTSD; found out that $94 \%$ had a pattern of "combat addiction" where nightmares or flashbacks experienced as a 'high' had alternated with periods of severe depression. ${ }^{27}$ Collins and Bailey studying a prison sample of 1140 males; established a relationship between PTSD and violent crime excluding armed combating. ${ }^{28}$ Here, the $2.3 \%$ who satisfied the strict criteria of PTSD showed a significantly higher chance of being arrested or imprisoned for a violent offence.

One ongoing problem in the scientific literature is the use of diverse methods (without uniformity) to assess rates of violence both among the mentally ill as well as the control groups. Some studies are based on self-reporting or participant's recollection of the events. These studies may underestimate the rates of violence due to participants being reluctant to admit resorting to violence, forgetting what they did in the past or lying. Some other researchers have relied upon the data in the criminal justice systems while yet others have not controlled multiple variables beyond substance abuse that contribute to violent behaviour such as stress, poverty, personal adversity or family history. The MacArthur Violent Risk Assessment Study was designed to eliminate such bias. ${ }^{29}$ This is considered as one of the first researches to address the design flaws of the earlier researches. The designers counted on three sources of information simultaneously in the assessment of rates of violence: interviewing the participants multiple times to assess selfreported violence on an on-going basis, verifying the participant's memory by crosschecking with multiple sources (such as family members, case managers) and finally getting information from arrest reports and 
hospital records. This study showed that $31 \%$ of people who had a so called "dual diagnosis" of substance abuse disorder and psychiatric disorder, committed at least one act of violence a year compared with $18 \%$ of people with a psychiatric disorder alone. This confirmed that substance abuse is a key contributor to violent behaviour. After controlling for substance abuse, rates of violence reported in the study may reflect factors common to a particular neighbourhood rather than the symptoms of a psychiatric illness. In two other best designed studies, investigators from the University of Oxford suggested that shared genetic vulnerability and common elements of social environment (poverty, early exposure to violence) were at least partially responsible for violent behaviour though rates of violence increased dramatically in those with a dual diagnosis of psychiatric disorder and substance abuse..$^{30,31}$ These two studies, taken together with MacArthur study suggest that violence by people with mental disorders stem from multiple overlapping factors interacting in complex ways. These include family history, personal stressors such as divorce or bereavement and socioeconomic factors such as poverty or homelessness. Substance abuse is often tightly attached to this scenario making it hard to tease apart the influence of other less obvious factors. The same view is supported by a recent study conducted by Jillian Peterson in 2014 with the patronage of American Psychological Association which is the largest scientific and professional organization representing psychology in the United States. $^{32}$

\section{CONCLUSION}

It is difficult to establish a firm relationship between mental disorder and crime though there are some exceptions. For example schizophrenia is the psychosis most associated with violence though actual numbers involved are very small. There is also an established association between psychopathic disorder and violence though violent behaviour is innately incorporated in to the definition of this disorder. Furthermore, though there is evidence that certain types/forms of mental disorder are associated with criminality, there is no conclusive proof that the offences have occurred as a result of the mental disorder. Although a subset of individuals with psychiatric disorders commits assaults and violent crimes, findings are inconsistent as to how much mental illness contributes in the context of substance abuse and other sociocultural and genetic factors. The vast majority of people with mental illness are not violent. The public is misinformed by the entertainment and news media about the link between mental illness and violence. These inaccurate beliefs about mental illness and violence lead to wide-spread stigma and discrimination.

\section{REFERENCES}

1. Teplin L (1984) Criminalising mental disorder: The comparative arrest rate of the mentally ill. American Psychologist, 39, 794803

Teplin L (1985) The criminality of the mentally ill. American Journal of Psychiatry, 142, 593-598

2. Bonta J, Law M, Hanson K (1998) The prediction of criminal and violent recidivism among mentally disordered offenders: A meta analysis. Psychological Bulletin, 123, 123-142

3. Coid J (1984) How many psychiatric patients in prison? British Journal of Psychiatry, 145, 78-86

4. Gunn J, Maden A, Swinton M (1991) Treatment needs of prisoners with psychiatric disorders. British Medical Journal, 303, 338-341

5. Gunn J, Robertson G, Dell S, Way C (1978) Psychiatric aspects of imprisonment. London: Academic Press

6. Taylor P (1986) Psychiatric disorders in London's life-sentenced offenders. British Journal of Criminology, 26, 63-78

7. Teplin L (1990) The prevalence of severe mental disorder among urban jail detainees: Comparison with the epidemiologic catchment area programme. American Journal of Public Health, 80, 663-669

8. Birmingham L, Mason D, Grubin D (1996) Prevalence of mental disorder in remand 
prisoners: Consecutive case study. British Medical Journal, 313, 1521-1524

9. Brooke D, Taylor C, Gunn J, Maden A, (1996) Point prevalence of mental disorder in unconvicted male prisoners in England and Wales. British Medical Journal, 313, 15241527

10. Singleton N, Meltzer H, Gatward R with Coid J, Deasy D (1998) Psychiatric Morbidity among Prisoners in England and Wales. London: The stationery Office.

11. Fazel S, Danesh J (2002) Serious mental disorder in 23,000 prisoners: A systematic review of 62 surveys. Lancet, 359, 545-550

12. Gosden N, Kramp P, Gabrielsen G, Sestoft D (2003) Prevalence of mental disorders among 15-17 year old male adolescent remand prisoners in Denmark. Acta Psychiatrica Scandinavica, 107, 102-110

13. Birmingham L, Gray J, Mason D, Grubin D (2000) Mental illness at reception into prison. Criminal Behaviour and Mental Health, 10, 77-87

14. Feldman P (1977) Criminal Behaviour. London: Wiley

15. Wormith J (1984) The controversy over the effects of long-term incarceration. Canadian Journal of Criminology, 26, 423-437

16. Brennan P, Mednick S, Hodgins S (2000) Major mental disorder and criminal violence in a Danish birth cohort. Archives of General Psychiatry, 57, 494-500

17. Steadman H, Cocozza J, Melick M (1978) Explaining the increased arrest rate among mental patients: The changing clientele of state hospitals. American Journal of Psychiatry, 135, 816-820

18. Toch H, Adams K (1989) The Disturbed Violent Offender. New Haven, CT: Yale University Press

19. Gibbens T (1981) Shoplifting. British Journal of Psychiatry, 138, 346-347

20. Taylor P, Gunn J (1984) Risk of violence among psychotic men. British Medical Journal, 288, 1945-1949
21. Foucault M (1978) About the concept of the dangerous individual in nineteenth century legal psychiatry. International Journal of Law and Psychiatry, 1, 1-18

22. Taylor P, Gunn J (1984) Risk of violence among psychotic men. British Medical Journal, 288, 1945-1949

23. Hafner H, Boker W (1982) Crimes of Violence by Mentally Abnormal Offenders. Cambridge: Cambridge University Press

24. Black D, Spinks P (1985) Predicting outcomes of mentally disordered and dangerous offenders. In D Farrington and $\mathrm{R}$ Tarling (eds) Prediction in Criminology. Albany: State University of New York Press

25. Hare R, McPherson L, Forth A (1988) Male psychopaths and their criminal careers. Journal of Consulting and Clinical Psychology, 56, 710-714

26. Jamieson L, Taylor P (2004) A reconviction study of special (high security) hospital patients. British Journal of Criminology, 44, 783-802

27. Solursh L (1989) Combat addiction: Overview of implications in symptom maintenance and treatment planning. Journal of Traumatic Stress, 2, 451-462

28. Collins J, Bailey S (1990) Traumatic stress disorder and violent behaviour. Journal of Traumatic Stress, 3, 203-220

29. Mental illness and violence http://www.health.harvard.edu/newsletter/ha rvard mental health letter/2011/january

30. Fazel S, et al. Journal of the American Medical Association. May 209, 2009

31. Fazel S, et al. Archives of General Psychiatry. September 2010

32. Jillian Peterson. Mental illness Not Usually Linked to Crime, http://www.apa.org/news/press/release/2014 /04/mental-illness-crime.aspx . 